\title{
Aluminium Tertiary Industry Waste And Ashes Samples For Development Of Zeolitic Material Synthesis
}

\author{
Denise A. Fungaro ${ }^{1, *}$ (1) , Katia C. Silva ${ }^{1}$ and Alaa El Din Mahmoud ${ }^{2,3}$ (b) \\ ${ }^{1}$ Instituto de Pesquisas Energéticas e Nucleares, IPEN-CNEN/SP, São Paulo, SP, Brazil \\ ${ }^{2}$ Environmental Sciences Department, Faculty of Science, Alexandria University, 21511 Alexandria, Egypt. \\ ${ }^{3}$ Green Technology Group, Faculty of Science, Alexandria University, 21511 Alexandria,Egypt.
}

\begin{abstract}
Wastes generated in large amounts have been recognized as sustainable sources of raw materials for the synthesis of adsorbents. The synthesis of zeolite through wastes recycling of two different ash sources (coal bottom ash and sugarcane waste ash) and industrial aluminum waste was evaluated. The molar ratio of $\mathrm{SiO}_{2} / \mathrm{Al}_{2} \mathrm{O}_{3}$ for zeolite $4 \mathrm{~A}$ formation was achieved by the addition of aluminum waste from tertiary industry as aluminum source. Coal bottom ash and sugarcane waste ash were used as a source of both silica and alumina. The synthesized materials were characterized using X-ray powder diffraction (XRD), scanning electron microscopy (SEM) and cation exchange capacity (CEC). The analysis of the properties of the products demonstrates that the by-products can be used to produce zeolite A. The utilization of synthesized zeolites as adsorbent for cadmium removal from aqueous solution was conducted following the concept of implementation of utilization of waste materials as a component of the circular economy in the wastewater sector.
\end{abstract}

Key words: non-conventional aluminum source; coal bottom ash; sugarcane waste ash; zeolite A; hazardous waste; adsorption

\section{INTRODUCTION}

Nowadays, commercial, and industrial activities generate enormous amount of solid waste materials as by-products. Most of the agro-industrial wastes are untreated and underutilized, therefore they are either disposed by landfilling or burning. Such unsustainable practices are the fast-growing problems causing significant negative impacts on environment, aquatic ecosystem, and human health.

The concept of utilization of waste materials as a component of the circular economy is a potential alternative to the disposal of these residues in landfill sites. Waste materials can be transformed into value-added material after modification by treatments such as chemical, thermal, and hydrothermal [1].

The aluminum recycling consists of secondary and tertiary aluminum industry. The secondary industry recovers metal by melting it in rotary kilns fueled by combustible oils, using sodium chloride as a flux. This process generates new slag, less rich in aluminum with amount about $20 \%$ of total volume. The tertiary industry uses different processes to recover the residual aluminum present in the aluminum waste of the secondary industry [2-4].

The wastes from tertiary aluminum are a rather complex mixture containing free metals, metal oxides, and salts. The disposal of this waste without any treatment can change the quality of groundwater and surface waters, mainly due to high level of ammonia [4]. Therefore, efforts have been made to utilize aluminium tertiary industry waste as an aluminum source in cost effective production [5-7].

The use of the $\mathrm{Al}$-containing waste as aluminum source in the synthesis of zeolites is an alternative to inadequate disposal. Zeolites have versatile applications including environmental, industrial, commercial, agricultural, and biomedical and, so are considered as value-added material. Various ecological materials, agro waste and manufacturing wastes have been used as a starting material in synthesizing zeolite $[8,9]$.

Among the various types of zeolite, zeolite like A-type is one of the most important molecular sieves, because presents high adsorption capacity and can easily exchange sodium ion with other cations, especially calcium. Furthermore, zeolite $\mathrm{A}$ is the most commercialized in the world, mainly used as an additive in laundry detergents $[10$, 11].

In general, commercial sodium aluminate is the most commonly chemical reagent used to control the $\mathrm{Si} / \mathrm{Al}$ ratio due to the low aluminum content in the wastes used for the synthesis of zeolite A. However, waste from another industry can be used as source of aluminum and so this procedure will enhance the environmental benefit by utilizing dual wastes [12-15].

In the present study, we investigate the uses of Al-containing waste as an alumina source and two types of ashes as source of silica and alumina. One ash sample is coal bottom ash, which is generated during the burning of coal pulverized in boiler and is disposed in landfill or is transported to the settling ponds with no further usage [16].

The other waste ash is generated in sugar and alcohol industry. Brazil and Egypt are the world's largest sugarcane producers. From sugarcane processing, bagasse and straw

$\begin{array}{ll}\text { Received } & \text { : March 12, 2021 } \\ \text { Revised } & \text { : April 25, 2021 } \\ \text { Accepted } & \text { : April 26, 2021 }\end{array}$


are calcined for power generation. After this stage, sugarcane bagasse ash is produced and is usually abandoned in the soil. Sugarcane bagasse ash has significant amorphous silica in its composition, which can be used in zeolite synthesis $[17,18]$.

Zeolitization of aluminosilicate residues is influenced by a wide range of parameters. Within this context, the objective of this study was optimizing the experimental conditions of zeolite A synthesis using Al-waste, as alternative to commercial sodium aluminate, and two ashes samples as mainly source of silica. The performance of the prepared zeolites in the removal of $\mathrm{Cd}^{2+}$ from water was also investigated.

\section{MATERIALS AND METHODS}

\subsection{Materials}

All chemicals used for experimental studies were of analytical grade. Coal bottom ash sample (CBA) was collected from Jorge Lacerda coal-fired power plant, located in Santa Catarina State, Brazil. Sugarcane waste ash (SWA) was donated by Cosan S.A., Brazil. The residue of aluminum tertiary industry (RA) was provided by the company Latasa Recycling located in São Paulo State, Brazil. A representative RA sample was mixed and homogenized by successive quartering. Sodium hydroxide (97\%) and sodium aluminate (100\%) obtained from Sigma-Aldrich Pty. Ltd. (Australia) were used in the preparation of zeolite synthesis.

\subsection{Zeolite synthesis using commercial sodium aluminate}

Synthesis of zeolite was executed by a two-step process. Firstly, $10 \mathrm{~g}$ of ash sample (CBA or SWA) was mixed with $\mathrm{NaOH}$ at 1:1.2 (wt\%) ratio. The mixture was heated at $500{ }^{\circ} \mathrm{C}$ for $1 \mathrm{~h}$. After cooling at room temperature, commercial sodium aluminate was added to the grinded mixture to control the molar ratio $\left(\mathrm{SiO}_{2} / \mathrm{Al}_{2} \mathrm{O}_{3}=1\right)$ and mixed with $100 \mathrm{~mL}$ deionized water. The mixture was then stirred at room temperature for $16 \mathrm{~h}$ and heated at $100{ }^{\circ} \mathrm{C}$ for $7 \mathrm{~h}$. After cooled at room temperature, the suspension was filtered and the solid was repeatedly washed with $1 \mathrm{~L}$ of deionized water and dried at $105{ }^{\circ} \mathrm{C}$ for $16 \mathrm{~h}$ [19]. The zeolites synthesized from CBA and SWA were named as ZCBA and ZSWA, respectively.

\subsection{Zeolite synthesis using residue of aluminum tertiary industry}

Fusion treatment was performed by placing $10 \mathrm{~g}$ of ash samples either CBA or SWA with RA and $\mathrm{NaOH}$. The ratio (ash + RA): $\mathrm{NaOH}$ was fixed at 1:1.2 (wt\%). The RA was added to adjust the molar ratio of $\mathrm{SiO}_{2} / \mathrm{Al}_{2} \mathrm{O}_{3}$ to 1 for zeolite $4 \mathrm{~A}$ formation. The mixture was heated at $500{ }^{\circ} \mathrm{C}$ for $1 \mathrm{~h}$. The fused sample was allowed to cool to ambient temperature and grounded into a fine powder using a mortar and pestle. Then, deionized water was added, and the mixture was stirred at room temperature for $16 \mathrm{~h}$. The resulting slurry formed was subjected to hydrothermal crystallization at $100{ }^{\circ} \mathrm{C}$ for $7 \mathrm{~h}$. After cooled at room temperature, the suspension was filtered and the solid was repeatedly washed with $1 \mathrm{~L}$ of deionized water and dried at $105^{\circ} \mathrm{C}$ for $16 \mathrm{~h}$. The zeolites synthesized from CBA and SWA and RA were named as ZCBA-RA and ZSWA-RA, respectively. The quantities of reagents used in the synthesis are shown in Table 1.

Table 1 Experimental conditions of zeolite synthesis

\begin{tabular}{lcc}
\hline \multirow{2}{*}{ Materials } & \multicolumn{2}{c}{ Ash Sample } \\
\cline { 2 - 3 } & SWA & CBA \\
\hline $\mathrm{RA}$ & $59.0 \mathrm{~g}$ & $25.0 \mathrm{~g}$ \\
$\mathrm{NaOH}$ & $82.8 \mathrm{~g}$ & $42.0 \mathrm{~g}$ \\
$($ Ash $+\mathrm{RA})$ & $69.0 \mathrm{~g}$ & $35.0 \mathrm{~g}$ \\
$\mathrm{H}_{2} \mathrm{O}$ & $690 \mathrm{~mL}$ & $350 \mathrm{~mL}$ \\
\hline
\end{tabular}

2.4 Characterization of ash samples and residual aluminum

The mineralogical compositions were determined by $\mathrm{X}$ -ray diffraction analyses (XRD) with an automated Rigaku Miniflex 2 diffractometer with $\mathrm{Cu}$ anode using $\mathrm{Co} \mathrm{Ka}$ radiation at $40 \mathrm{kV}$ and $20 \mathrm{~mA}$ over the range $(2 \theta)$ of $5-80^{\circ}$ with a scan time of $0.5 \% \mathrm{~min}$. The chemical composition was determined by X-ray fluorescence (XRF) in Rigaku RIX- 3000 equipment. Thermal analysis was performed by thermogravimetry on the Mettler-Toledo equipment model TGA/SDTA 851 , with heating of $10^{\circ} \mathrm{C} / \mathrm{min}$. Each sample $(21.79 \mathrm{mg})$ was heated from 25 to $1200^{\circ} \mathrm{C}$ at a heating rate of $5{ }^{\circ} \mathrm{C} \cdot \mathrm{min}^{-1}$, under a nitrogen flush $\left(50 \mathrm{~mL} \cdot \mathrm{min}^{-1}\right)$. The scanning electron micrographs were performed using a Hitachi TM-3000 microscope. The particle size of the materials was measured using a laser based particle size analyser, namely a Malvern MSS Mastersizer 2000 Ver. 5.54. Cation exchange capacity (CEC) was determined by a previously described procedure [19].

The chemical composition of coal bottom ash and sugarcane waste ash has been reported in previous paper and the data are summarized in Table 2 [20-22]. The particle size distributions of materials are given in Table 3.

Table 2 Chemical composition (wt\%) of ash simples

\begin{tabular}{ccc}
\hline \multirow{2}{*}{ Components } & \multicolumn{2}{c}{ Ash Sample } \\
\cline { 2 - 3 } & $\mathrm{CBA}$ & SWA \\
\hline $\mathrm{SiO}_{2}$ & 49.6 & 81.6 \\
$\mathrm{Al}_{2} \mathrm{O}_{3}$ & 27.0 & 7.94 \\
$\mathrm{Fe}_{2} \mathrm{O}_{3}$ & 10.9 & 2.31 \\
$\mathrm{~K}_{2} \mathrm{O}$ & 4.40 & 2.10 \\
$\mathrm{TiO}_{2}$ & 1.90 & 0.67 \\
$\mathrm{Na}_{2} \mathrm{O}$ & 1.90 & 0.26 \\
$\mathrm{MgO}$ & 1.30 & 1.26 \\
Others & $\leq 0.70$ & $\leq 1.07$ \\
\hline
\end{tabular}

Table 3 Particle size distributions of the ash samples

\begin{tabular}{ccccc}
\hline $\begin{array}{c}\text { Ash } \\
\text { Sample }\end{array}$ & $\begin{array}{c}\mathrm{D}_{10} \\
(\mu \mathrm{m})\end{array}$ & $\begin{array}{c}\mathrm{D}_{50} \\
(\mu \mathrm{m})\end{array}$ & $\begin{array}{c}\mathrm{D}_{90} \\
(\mu \mathrm{m})\end{array}$ & $\begin{array}{c}\mathrm{D}[3,2] \\
(\mu \mathrm{m})\end{array}$ \\
\hline CBA & 50.238 & 178.25 & 447.744 & 86.984 \\
SWA & 12.17 & 62.528 & 208.14 & 26.084 \\
\hline
\end{tabular}




\subsection{Adsorption Application}

Zeolites synthesized was used for adsorption studies. Equilibrium adsorption experiment was performed using various concentrations of cadmium (50 to $1460 \mathrm{mg} \mathrm{L}^{-1}$ ) solution. A mixture of $0.25 \mathrm{~g}$ of zeolitic material (ZCBA-RA or ZSWA-RA) with $25 \mathrm{~mL}$ of metal ion solution of various initial concentrations was shaken at $120 \mathrm{rpm}$ for $24 \mathrm{~h}$ at $25{ }^{\circ} \mathrm{C}$. The collected samples were then filtrate and the concentration in the filtrate solution was analyzed using inductively coupled plasma optical emission spectrometry (Spectro ARCOS, Spectro Analytical Instruments, Kleve, Germany). All experiments were performed in duplicate.

The adsorption capacity of the adsorbent was calculated using Eq. (1) [23, 24]:

$$
q_{e}=\frac{\mathrm{V}\left(\mathrm{C}_{\mathrm{o}}-\mathrm{C}_{\mathrm{e}}\right)}{\mathrm{M}}
$$

Where $q_{e}$ is the amount of metal adsorbed per unit mass of adsorbent at equilibrium $\left(\mathrm{mg} \mathrm{g}^{-1}\right), C_{o}$ and $C_{e}$ are the initial and equilibrium concentrations, respectively $\left(\mathrm{mg} \mathrm{L}^{-1}\right)$; $V$ the volume of the adsorbate solution added (L) and $\mathrm{M}$ the amount of the adsorbent used $(\mathrm{g})$.

The data of the isotherm adsorption equilibrium were fitted using nonlinear equations of Langmuir and Freundlich models $[25,26]$. The determination coefficient $\left(\operatorname{Radj}^{2}\right)$ was used to determine the best-fitting isotherm to the experimental data. In addition, the Chi-square $\left(c^{2}\right)$ test was employed, the lowest values were used to validate the applicability of isotherms tested [27].

\section{RESULTS AND DISCUSSION}

\subsection{Characterizations of residual aluminum waste}

The required $\mathrm{Al}^{3+}$ amount for the preparation of zeolite was mainly provided by $\mathrm{Al}$-containing waste. The waste from aluminum tertiary industry consists of a black powder (Figure 1) and a detailed characterization was described elsewhere [28]. Briefly, the main chemical composition was $\mathrm{Al}_{2} \mathrm{O}_{3} 27.8$ wt.\%, $\mathrm{Cl} 17.4$ wt.\%, $\mathrm{Na}_{2} \mathrm{O} 16.7$ wt.\%, $\mathrm{SiO}_{2} 3.78$ wt. $\%$ and $\mathrm{MgO}, \mathrm{KO}_{2}, \mathrm{Fe}_{2} \mathrm{O}_{3} \leq 2.37$ wt.\%. The mainly coarse particle size $\left(D_{90}\right)$ was $\sim 450 \mu \mathrm{m}$. The total content of aluminum is distributed in different crystalline phases, namely, corundum $\left(\mathrm{Al}_{2} \mathrm{O}_{3} ;\right)$, sylvite $(\mathrm{KCl})$, spinel $\left(\mathrm{MgAl}_{2} \mathrm{O}_{4} ;\right)$, halite $(\mathrm{NaCl})$ and fayalite $\left(2 \mathrm{FeO} \cdot \mathrm{SiO}_{2}\right)$. The high $\mathrm{Cl}$ and $\mathrm{Na}$ content are attributable to the employ of high amounts of salt (mainly $\mathrm{NaCl}$ and $\mathrm{KCl}$ ) in the melting process to get a higher aluminum recovery [3].

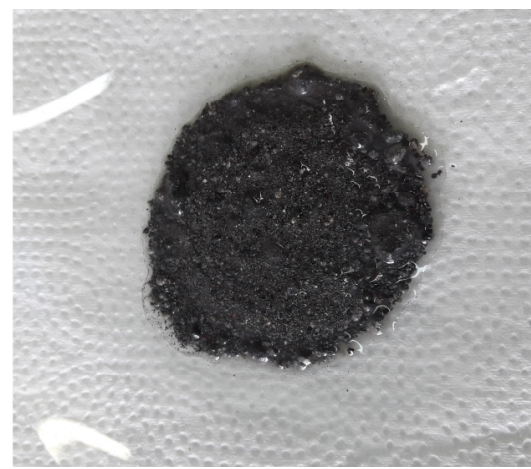

Fig. 1. Macroscopic appearance of aluminum waste sample
The thermal stabilities and decomposition temperatures of RA were investigated under an inert atmosphere and their TGA/DTG thermograms were given in Figure 2. An only peak was observed at $1040{ }^{\circ} \mathrm{C}$ and a loss of $\sim 31 \%$ mass was detected. This loss occurs in a single step due to chloride compounds decomposition in a nonoxidative process. The amount of $\sim 69 \%$ residue at the end of the experiment indicates that the sample has high inorganic compounds content with a thermal stability.

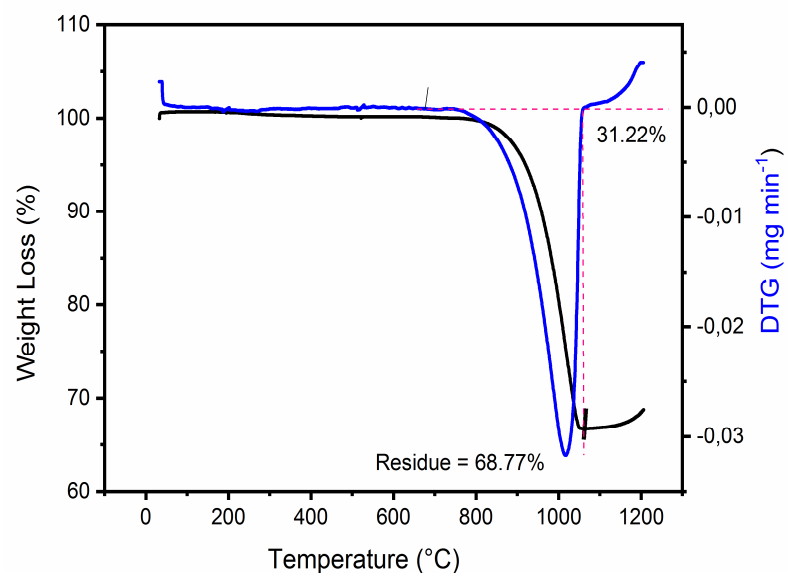

Fig. 2. Thermogravimetric analysis curves in $\mathrm{N}_{2}$ atmosphere for RA

\subsection{Mineralogical composition of the ash samples}
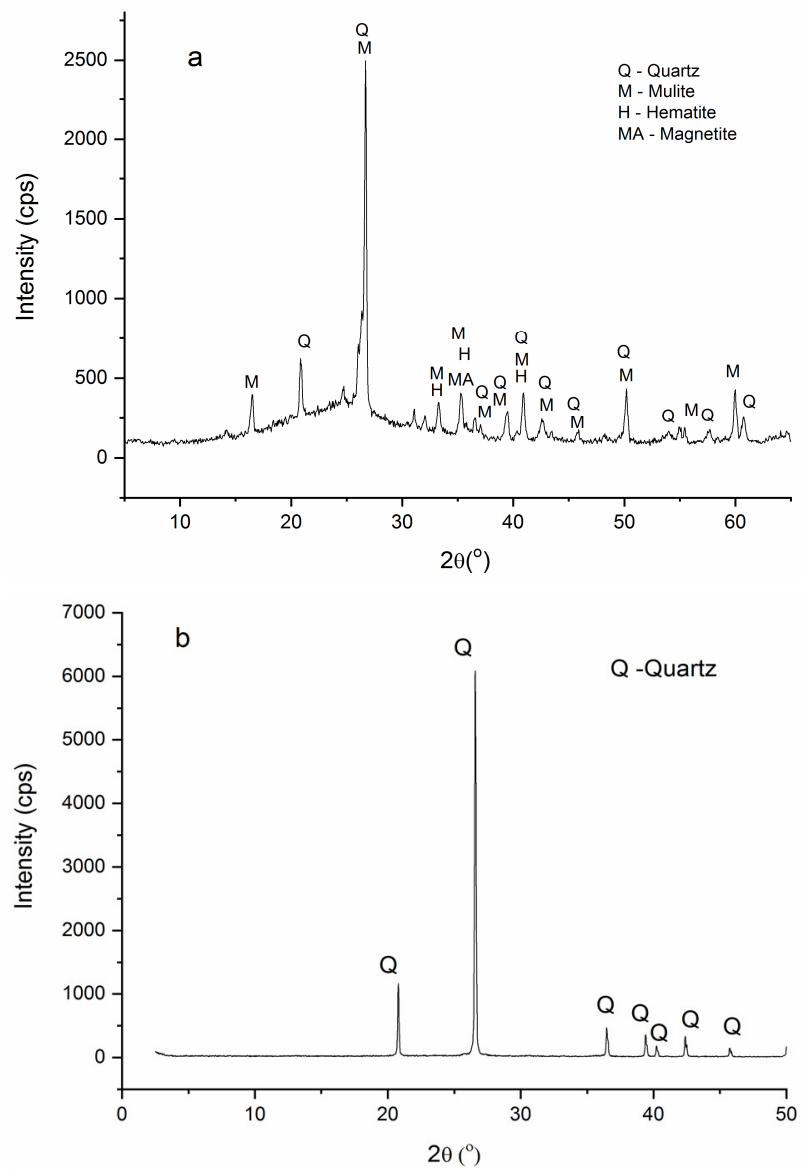

Fig. 3. X-ray diffractograms of: (a) coal bottom ash; (b) sugarcane waste ash 

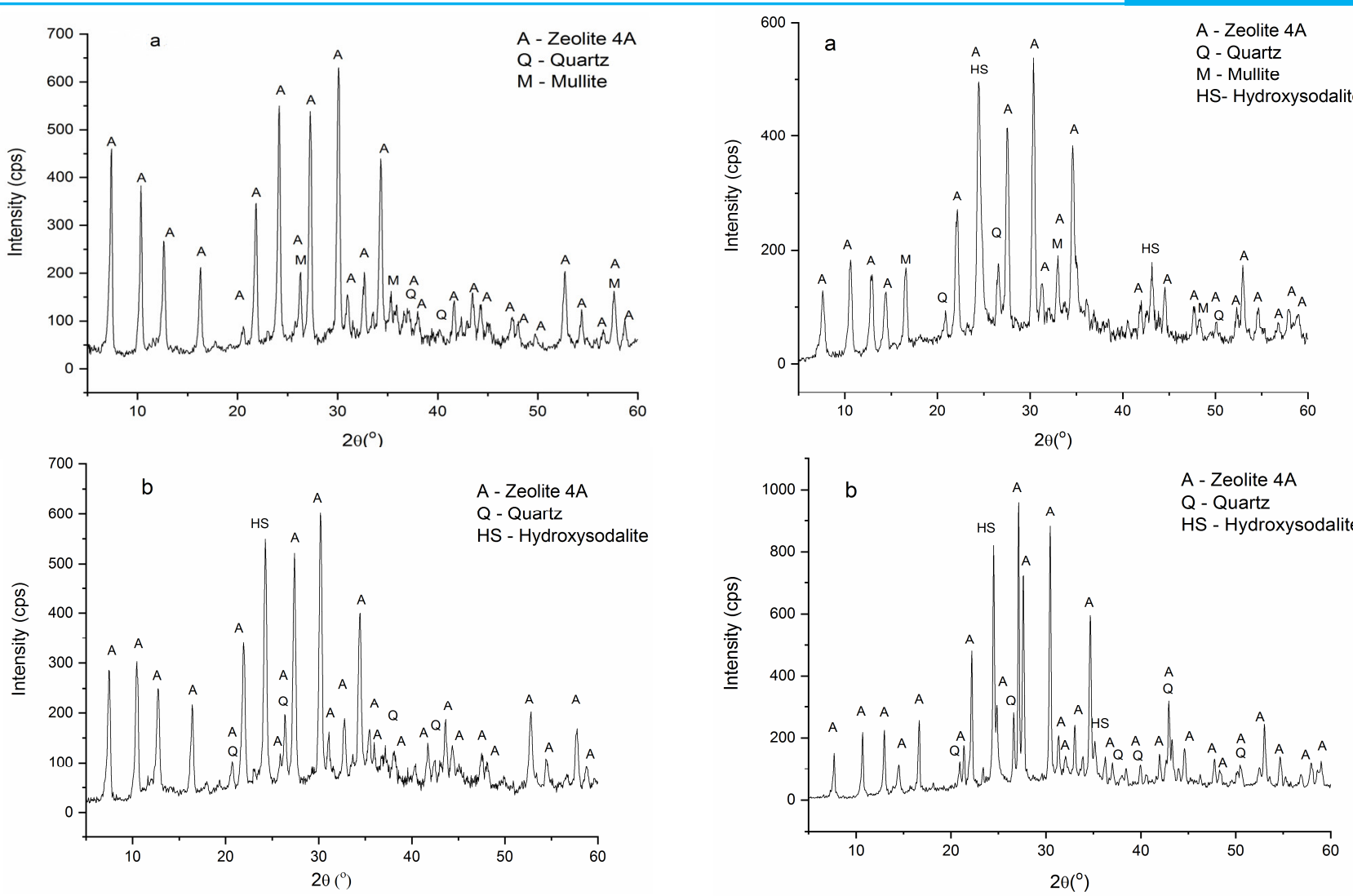

Fig. 4. X-ray diffractograms of ash-based zeolites from aluminium waste (a) ZCBA-RA; (b) ZSWA-RA

The mineralogy result of CBA is displayed in Figure 3a, indicating the presence of quartz, mullite, hematite, magnetite, and halo with amorphous content. On the other hand, the XRD pattern of SWA sample (Figure $3 b$ ) presents only peaks relative to crystalline silica, indicating that the burning temperature of the bagasse at the sugar mill was above $800^{\circ} \mathrm{C}$.

The method for obtaining Na-A zeolite was optimized using fly ash as raw material and commercial sodium aluminate. The fusion method was applied to facilitate decomposition of $\mathrm{Si}$ and Al-rich crystalline phases and form soluble aluminates and silicates. Sodium aluminate was added to control the $\mathrm{Si} / \mathrm{Al}$ molar ratio of 1.0 [19].

This method was adapted for the use of aluminum waste as an alternative aluminum source to the commercial reagent. The residue was added with ash sample and $\mathrm{NaOH}$ in the fusion step considering that the mineralogy of $R A$ predominantly consisted of crystalline phases of aluminum. Thus, a melting step is necessary so that the residual aluminum dissolves and reacts with the silicon present in the ashes to form the sodium aluminosilicate sufficient to form Na-A zeolite. The fusion temperature and time applied on the zeolitization process were optimized in a previous study $[20,28]$.

Furthermore, XRD was used to identify the crystalline phases of the synthesized zeolites using residual aluminum waste (Figure 4). The diffractograms of products synthesized from ash samples and sodium aluminate are also presented for comparison (Figure 5).

The results indicated that all products contain zeolite $\mathrm{A}$ as the major constituent phase, whereas quartz, mullite

Fig. 5. X-ray diffractograms of ash-based zeolites from sodium aluminate (a) ZCBA; (b) ZSWA

and hydroxysodalite were found as minor phases. Quartz and mullite is attributed to the remaining content of these compounds in the ash samples and aluminum waste even after fusion, and hydroxysodalite is formed because is thermodynamically more stable than zeolite A [29].

\subsection{Morphological analysis of the ash samples and synthesized zeolites}

The morphologies of CBA and SWA are shown in Figure $6 \mathrm{a}$ and Figure $6 \mathrm{~b}$, respectively. SEM images of both samples show heterogeneous material with irregular shapes. The spherical shape of coal bottom ash particles (Figure 6a) is typical of coal ashes and can be attributed to their amorphous coating formed because of relatively abrupt cooling after combustion.

It can be seen in SEM image of SWA (Figure 6b) that the sample is rich in angular-shaped particles, which are probably silica ones. The roughness is associated with the release of organic matter during the bagasse burning process for the generation of energy in the sugar alcohol industry. In addition, a wide particle size range can be observed (5-500 $\mu \mathrm{m})$. Other SWA samples showed similar morphologies $[30,31]$.

The morphology of the synthetic ZCBA-RA and ZSWA-RA zeolites are presented in Figure $6 \mathrm{c}$ and $6 \mathrm{~d}$, respectively. The typical cube shaped crystals of zeolite A is observed in addition to amorphous-looking material from raw materials in zeolitic material. The zeolite crystals precipitate on the ash particles of coal and of sugarcane waste during alkaline treatment. Other crystals observed with not defined morphology is related probably to hydroxysodalite phase. 

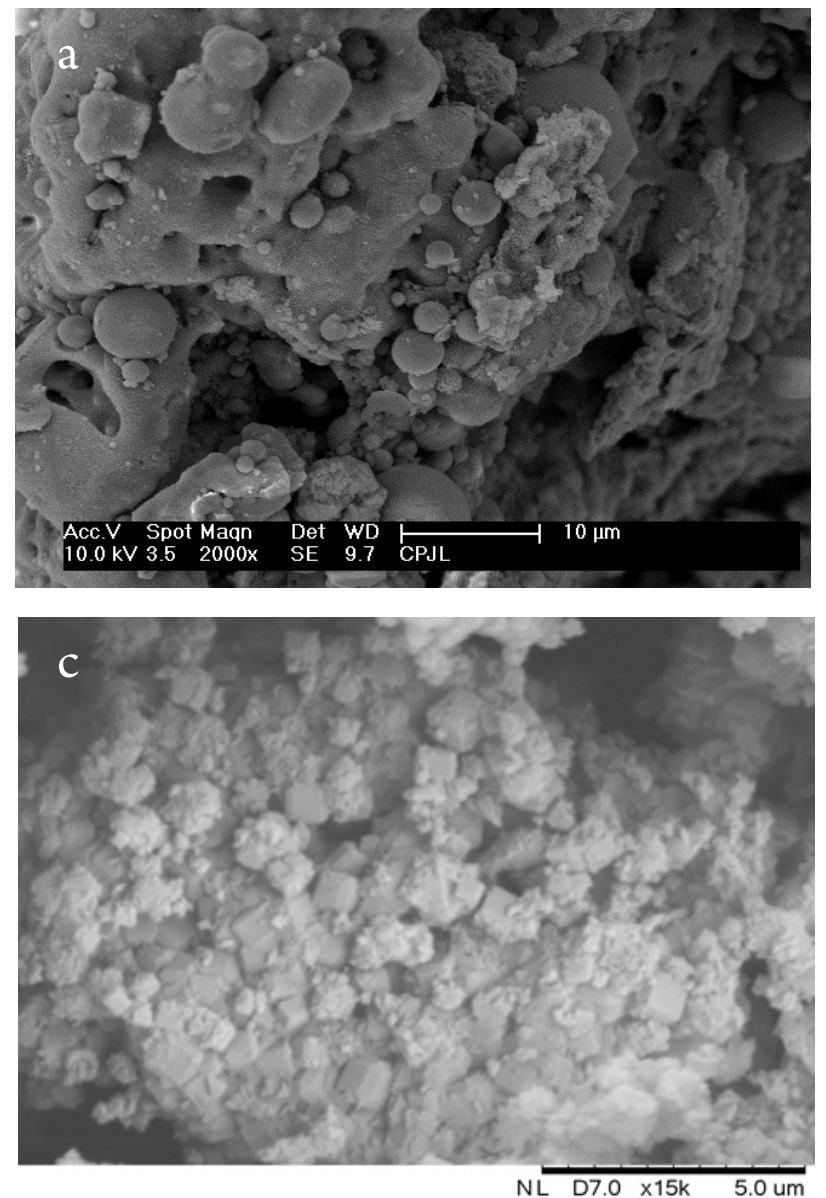

Fig. 6. Micrographs of (a) coal bottom ash, (b) sugarcane waste ash; (c) ZCBA-RA; (d) ZSWA-RA

\subsection{Cation exchange capacity of zeolitic materials}

Table 4 shows the characterization of the products in terms of cation exchange capacity (CEC) and an estimate of zeolite content in the synthesized materials. The CEC was used to estimate semi-quantitative data of the zeolite content in the synthesized materials by comparing the CEC value obtained with pure commercial zeolite A $\left(4.55 \mathrm{meq} \mathrm{g}^{-1}\right)$. This estimate considers that CEC values for minor phases are negligible [32].

Table 4 Cation exchange capacity and percentage of conversion (PC) of wastes into zeolite products

\begin{tabular}{ccc}
\hline Zeolite & CEC $\left(\mathrm{meq}^{-1}\right)$ & PC $(\%)$ \\
\hline \multicolumn{3}{c}{ addition of aluminum residue } \\
ZCBA-RA & 3.04 & 66.8 \\
ZSWA-RA & 3.18 & 69.8 \\
& addition of sodium aluminate \\
ZCBA & 3.54 & 77.8 \\
ZSWA & 3.67 & 80.7 \\
\hline
\end{tabular}

It can be seen that the values of cation exchange capacity of zeolites from ashes and aluminum waste did not show a significant difference and, in turn, the content of formation of zeolite A was around $70 \%$ for the two types of ash. The CEC values of zeolite products synthesized using
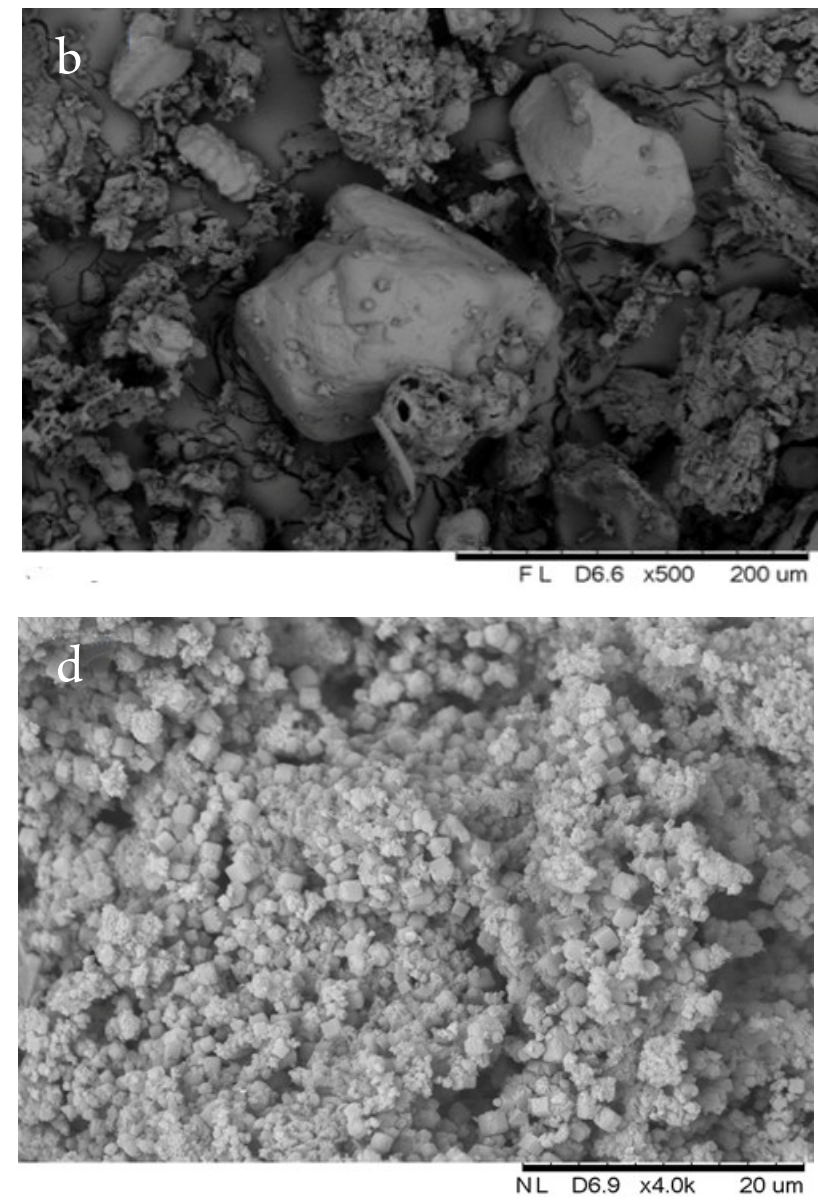

commercial sodium aluminate for the adjustment of the $\mathrm{Si} / \mathrm{Al}$ ratio of the two ash samples were around $80 \%$.

Interestingly, zeolitic material synthesized from fly ash and aluminum waste presented a CEC value ( $3.34 \mathrm{meq}^{-1}$ ) similar to that obtained in the present study for zeolite from coal bottom ash and zeolite from sugarcane ash [20, 28]. The obtained experimental results clearly demonstrated that at equal synthesis condition the characteristics of the ash samples (particle size, $\mathrm{Si}$ and $\mathrm{Al}$ available in the feedstock, impurities, etc.) did not influence the zeolitization process.

It obvious that the decrement of CEC values of zeolitic materials obtained from residual aluminum waste compared to commercial sodium aluminate is because the residue presents a considerable content of aluminum species in crystalline forms, which are difficult to dissolve and also presents impurities. Besides that, the total aluminum added in the synthesis process with commercial sodium aluminate is solubilized and available.

The purification of aluminum wastes with sulphuric or hydrochloric acids is applicable to remove impurities to produce high purity zeolite. However, such acid treatment might be a negative factor for zeolite crystallization $[15,33]$. In addition, acid leaching generates significant volumes of liquid wastes that lead to a relatively high production cost.

\subsection{Adsorption Studies}

Eco-friendly adsorbents include the materials obtained from industrial waste recognized as low-cost sources. Among them, zeolites synthesized from wastes have confirmed their ability to remove heavy metals comparatively with natural or 


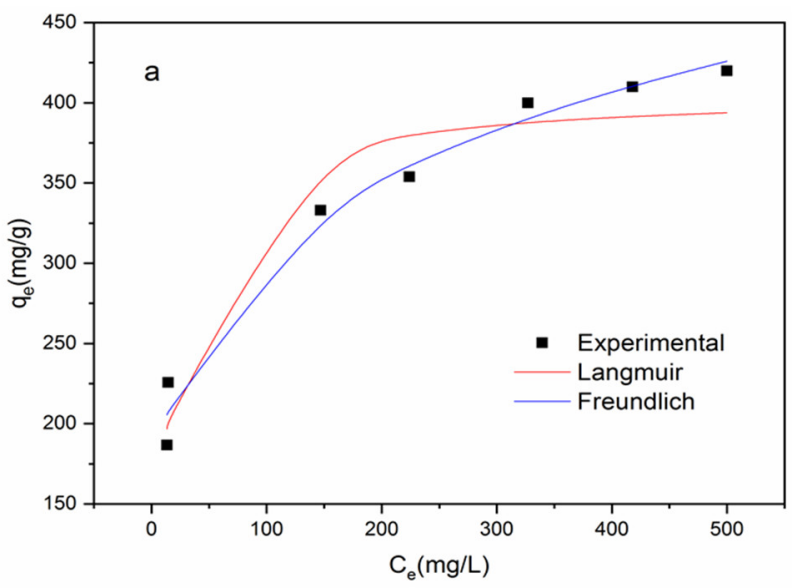

Fig. 7. Adsorption isotherms of $\mathrm{Cd}^{2+}$ on (a) ZCBA-RA and (b) ZSWA-RA commercial zeolites $[8,34]$. Therefore, the removal of $\mathrm{Cd}^{2+}$, which act as endocrine disruptors, from aqueous solutions was performed using zeolitic material synthesized from the two ash samples and aluminum waste (ZCBA-RA and ZSWA-RA).

The Langmuir and Freundlich models were adjusted to experimental data through the nonlinear estimation method. Figure $7 \mathrm{a}$ and Figure $7 \mathrm{~b}$ shows the adsorption isotherms for $\mathrm{Cd}^{2+}$ on zeolites ZCBA-RA and ZSWA-RA, respectively. The isotherm parameters determined for both adjustments were determined using nonlinear expressions and are shown in Table 5 .

Table 5 Parameters of the Langmuir and Freundlich models for adsorption of $\mathrm{Cd}^{2+}$ onto ZCBA-RA and ZSWA-RA

\begin{tabular}{ccc}
\hline Parameters & ZSWA-RA & ZCBA-RA \\
\hline $\mathrm{k}_{L}\left(m g g^{-1}\right)$ & Langmuir & \\
$b_{L}\left(L m g^{-1}\right)$ & $7.41 \times 10^{-2}$ & $7.00 \times 10^{-2}$ \\
$R_{a j}^{2}$ & 0.625 & 0.912 \\
$X^{2}$ & 18.5 & 11.2 \\
& Freundlich & \\
$k_{F}\left(m g g^{1}\right)\left(L m g^{1}\right)^{1 / n}$ & 131 & 121 \\
$1 / n$ & 0.189 & 0.202 \\
$R_{a j}^{2}$ & 0.945 & 0.981 \\
$X^{2}$ & 3.21 & 3.61
\end{tabular}

The Freundlich model presented the highest value for $\mathrm{R}_{\mathrm{aj}}{ }^{2}$ (coefficient of determination) and the lowest value for $\chi^{2}$ (chi-square) when compared to the Langmuir model and, therefore, is the most appropriate model to describe the adsorption balance of $\mathrm{Cd}^{2+}$ onto ZCBA-RA and ZSWA-RA (Table 5). Thus, homogeneous, and heterogeneous distributions can occur by adsorption in monolayer and multilayer, in a process that can occur simultaneously or subsequently in order of time, both at random [35].

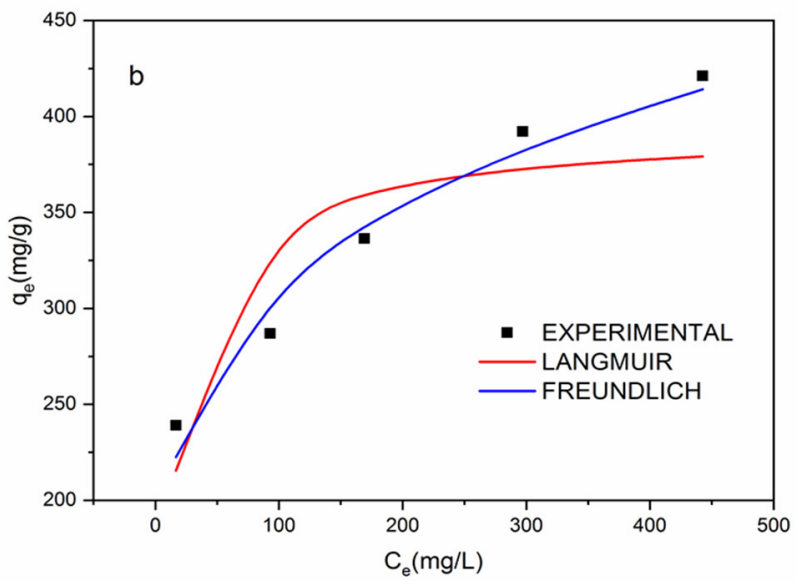

\section{CONCLUSIONS}

This study is a management strategy for contribute to the sustainable development goals (SDG's), specifically, SDG 12: "Reduce waste generation through prevention, reduction, recycling, and reuse". On the basis of the results, it can be stated that zeolite A from two different ash and industrial aluminum waste was successfully synthesized by fusion method.

The synthesized zeolites exhibited high cation exchange capacities and suitable adsorption properties, resulting in potential adsorbents for the removal of cadmium from aqueous solutions. Nonlinear Langmuir and Freundlich equilibrium models were employed to analyze the adsorption data. The maximum adsorption capacity was 391 and $406 \mathrm{mg} \mathrm{g}^{-1}$ for zeolites from sugarcane waste ash: $\mathrm{Al}$ waste and coal bottom ash: $\mathrm{Al}$ waste, respectively, according to the Langmuir isotherm model. The developed zeolitization process would enable to reduce the amount of hazardous aluminum waste, sugarcane ash waste and coal bottom ash, which are generally disposed in landfill or secure deposits involving high cost, preserving contamination, especially groundwater and hence helping the sustainability of environment.

\section{AUTHOR INFORMATION}

\section{Corresponding Author}

*Email: dafungaro@gmail.com

\section{ORCID}

Denise Alves Fungaro : : 0000-0003-1618-0264

Alaa El Din Mahmoud :0000-0001-6530-9816

\section{ACKNOWLEDGEMENTS}

The authors are grateful to Jorge Lacerda and Charqueadas Coal-fired Power Plants and Company Latasa Recycling for providing samples.

\section{REFERENCES}

[1] Hossain, N., Bhuiyan, M. A., Pramanik, B. K., Nizamuddin, S., Griffin, G. 2020. "Waste materials for wastewater treatment and waste adsorbents for biofuel and cement supplement applications: A critical review.” J. Clean. Prod. 255, 120261. 
[2] Gil, A., Korili, S. A. 2016. "Management and valorization of aluminium saline slags: current status and future trends.” Chem. Eng. J., 289, 74-84.

[3] Shinzato, M. C., Hypolito, R. 2005. "Solid waste from aluminum recycling process: characterization and reuse of its economically valuable constituents." Waste Manag., 25, 37-46.

[4] Shinzato, M. C., Hypolito, R. 2016. "Effect of disposal of aluminum recycling waste in soil and water bodies." Environ. Earth Sci., 75, 628-638.

[5] López-Delgado, A., Tayibi, H. 2012. "Can hazardous waste become a raw material? The case study of an aluminium residue: a review." Waste Manag. Res., 30, 474-484.

[6] Sánchez-Hernández, R., López-Delgado, A., Padilla, I., Galindo, R., López-Andrés, S. 2016. “One-step synthesis of NaP1, SOD and ANA from a hazardous aluminum solid waste.” Microp. Mesop. Mater., 226, 267-277.

[7] Sánchez-Hernández, R., Padilla, I., López-Andrés, S., López-Delgado, A. 2017. "Eco-friendly bench-scale zeolitization of an Al-containing waste into gismondine-type zeolite under effluent recycling." J. Clean. Prod., 161, 792-802.

[8] Khaleque, A., Alam, M. M., Hoque, M., et al. 2020. "Zeolite synthesis from low-cost materials and environmental applications: A review.” Environ. Adv., 2, 100019.

[9] Mallapur, V. P., Oubagaranadin, J. U. K. 2017. “A brief review on the synthesis of zeolites from hazardous wastes.” T. Indian Ceram. Soc., 76, 1-13.

[10] Cruz, T. J. T., Melo, M. I. S., Pergher, S. 2020. "Optimization of parameters and methodology for the synthesis of LTA-type zeolite using light coal ash.” Appl. Sci.10, 7332.

[11] Collins, F., Rozhkovskaya, A., Outram, J. G., Millar, G. J. 2020. "A critical review of waste resources, synthesis, and applications for Zeolite LTA." Micropor. Mesopor. Mat., 291, 109667.

[12] Kang, Y., Swain, B., Im, B., Yoon, J.-H., Park, K. H., Lee, C. G., Kim, D. G. 2019. "Synthesis of zeolite using aluminum dross and waste lcd glass powder: a waste to waste integration valorization process." Metals, 9, 1240.

[13] Ahmedzeki, N. S., Abbas, M. N., Joodee, A. M., Jaed, Y. M. 2018. "Waste resources utilization for zeolite A synthesis.” J. Chem. Technol. Metal., 53, 239-244.

[14] Shoumkova, A., Stoyanova, V. 2013. "SEM-EDX and XRD characterization of zeolite $\mathrm{NaA}$ synthesized from rice husk and aluminum scrap by different procedures for preparation of the initial hydrogel." J. Porous Mater., 20, 249-255.

[15] Anuwattana, R., Khummongkol, P. 2009. "Conventional hydrothermal synthesis of $\mathrm{Na}-\mathrm{A}$ zeolite from cupola slag and aluminum sludge.” J. Hazard. Mater.,166, 227-232.

[16] Levandowski, J., Kalkreuth, W. 2009. “Chemical and Petrographical Characterization of Feed Coal, Fly Ash and Bottom Ash from the Figueira Power Plant, Paraná, Brazil.” Int. J. Coal Geol., 77, 269-281.
[17] Moisés, M. P., Silva, C. T. P., Meneguin, J. G., Girotto, E. M., Radovanovic, E. 2013. "Synthesis of zeolite NaA from sugarcane bagasse ash.” Mater. Lett., 108, 243246.

[18] Purnomo, C. W., Salim, C., Hinode, H. 2012. "Synthesis of pure $\mathrm{Na}-\mathrm{X}$ and $\mathrm{Na}-\mathrm{A}$ zeolite from bagasse fly ash.” Micropor. Mesopor. Mat.,162, 6-13.

[19] Izidoro, J. C., Fungaro, D. A., Abbott, J. E., Wang, S. 2013. "Synthesis of zeolites X and A from fly ashes for cadmium and zinc removal from aqueous solutions in single and binary ion systems.” Fuel, 103, 827-834.

[20] Silva, K. C. 2019. "Synthesis of value-added zeolitic material from alternative sources of silicon and aluminum." MSc. Thesis. Instituto de Pesquisas Energéticas e Nucleares, São Paulo, SP, Brazil Portuguese.

[21] Alves, R. H., Reis, T. V. S., Rovani, S., Fungaro, D. A. 2017. "Green synthesis and characterization of biosilica produced from sugarcane waste ash." J. Chem., 2017, Article ID 6129035.

[22] Bertolini, T. C. R., Izidoro, J. C., Magdalena, C. P., Fungaro, D. A. 2013. "Adsorption of crystal violet dye from aqueous solution onto zeolites from coal fly and bottom ashes." Orbital: Electron. J. Chem., 5, 179-191.

[23] Mahmoud, A. E. D., Fawzy, M., Hosny, G.et al. 2020. "Equilibrium, kinetic, and diffusion models of chromium(VI) removal using Phragmites australis and Ziziphus spina-christi biomass.” Int. J. Environ. Sci. Technol. https://doi.org/10.1007/s13762-020-02968 $-7$.

[24] Mahmoud, A. E. D, Fawzy, M., Radwan, A., 2016. "Optimization of Cadmium $\left(\mathrm{Cd}^{2+}\right)$ removal from aqueous solutions by novel biosorbent." Int. J. Phytoremediation, 18, 619-625.

[25] Langmuir, I., 1918. "The adsorption of gases on plane surfaces of glass, mica and platinum.” J. Am. Chem. Soc. 40, 1361-1403.

[26] Freundlich, H. M. F. 1906. "Over the adsorption in solution.” J. Phys. Chem. 57, 1100-1107.

[27] Ho, Y. S. 2004."Selection of optimum sorption isotherm.” Carbon. 42, 2115-2116.

[28] Fungaro, D. A., Izidoro, J. A.; Guilhen, S. N.; Silva, K. C.; WANG, S. 2018. "Synthesis of nanocrystalline zeolite Na-A from coal fly ash and different aluminum sources: application for heavy metals removal." In: Gray, M. (Ed.) Coal Fly Ash: Properties, Applications and Performance. Hauppauge, N.Y.: Nova Science Publishers, Chapter 4.

[29] Subotic, B., Sekovanic, L. J. 1986. "Transformation of zeolite A into hydroxysodalite.” J. Cryst. Growth., 75, 561-572.

[30] Mansaneira, E. C., Schwantes-Cezario, N., BarretoSandoval, G. F., Martins-Toralles, B. 2017. "Sugar cane bagasse ash as a pozzolanic material” DYNA, 84, 163171.

[31] Faria, K. C. P.; Gurgel, R. F.; Holanda, J. N. F. 2012. "Recycling of sugarcane bagasse ash waste in the production of clay bricks.” J. Environ. Manage., 101, 7-12. 
[32] Querol, X., Moreno, N., Umaña, J. C., Alastuey, A., Hernández, E., López-Soler, A., Plana, F. 2002. "Synthesis of zeolites from coal fly ash: an overview." Int. J. Coal Geol. 50, 413-423.

[33] Ma, D., Wang, Z., Guo, M., Zhang, M., Liu, J. 2014. "Feasible conversion of solid waste bauxite tailings into highly crystalline 4A zeolite with valuable application." Waste Manag.34, 2365-2372.

[34] Harja, M., Ciobanu, G. 2020. "Eco-friendly nano-adsorbents for pollutant removal from wastewaters." In: Kharissova O., Martínez L., Kharisov B. (eds). Handbook of Nanomaterials and Nanocomposites for Energy and Environmental Applications. Switzerland AG: Springer.

[35] Din, A. M., Hameed, B. H. 2010. "Adsorption of methyl violet dye on acid modified activated carbon: isotherms and thermodynamics." J. Appl. Sci. in Environ. Sanit., 5,161-170. 